\title{
ELEMENTS OF A SOCIOLOGY FOR NURSING: CONSIDERATIONS ON CAREGIVING AND CAPITALISM ${ }^{1}$
}

\author{
Timothy Diamond \\ Northwestern University
}

Mid-American Review of Sociology, 1984, Vol. 1X, No. 1:3-21

Four questions are raised about contemporary nursing. In exploring these, a particular sociological method is applied, that of preserving the presence of the nurse as subject throughout the analysis. The four questions are: 1) are nursing assistants nurses? 2) are foreigntrained nurses nurses? 3) are nurses the subject of the nursing shortage debate? 4) is nursing medicine? I start from examples of nurses' actual work situations, drawn from participant observation research, then discuss how in each example nursing work undergoes a transformation as it becomes defined by the administrative logic that surrounds it, particularly as it is placed into the terms of capitalist medicine. Answers to the questions are posed through the examination of two alternative approaches to the meaning of nursing in society, drawn from liberal and radical perspectives in sociology and feminist theory. They provide different answers to the questions. A sociology "for" nursing is discussed as one which offers nurses frame of reference in which to see their work in terms of both alternatives.

This paper applies some contributions from British, Canadian, and American sociology and socialist feminism to certain controversies currently being discussed by nurses and about nursing in the United States. The notion of a sociology "for" nursing is derived from the writings of Dorothy Smith $(1974,1979,1981)$, primarily "A Sociology for Women" (1979). In Smith's conception, a sociology "for" is not the same as a sociology "of" or "about" a group of people. She outlines a method that, in an effort to "preserve the presence of the subject" (1974:43), begins with actual people and traces linkages between their everyday situations and more general characteristics of the society, particularly the relations of capitalism, which contextualize everyday life. Smith raises one of the fundamental questions posed by Marx and Engels (Smith, 1979:184): "How does it happen that (individuals" social relations) assume an independent existence over them? And the 
forces of their own life overpower them?"2 She proposes that by starting from people located in actual work situations we can explore how their lives become objectified by the administrative processes of corporate capitalism and how, along the way, subjects get turned into objects. A sociology for nursing would be concerned primarily with how the work of nurses gets objectified by the administrative structures and language which encase it. From among the different domains in which this might be explored, this paper focuses on four issues or elements of the process.

The empirical dimension of the paper is based on a participant observation project. Over the last three years I have engaged in a study of nursing assistants ${ }^{3}$ and their work in nursing homes. I trained in a nursing assistant school, then worked in three homes over an eighteenmonth period. Although the issue of who possesses a legitimate right to speak on behalf of all nurses is open to debate, in this paper I introduce some subjects who are not typically represented in the formal literature on nursing. From their vantage points certain issues can be raised about the whole field of nursing. At the same time, certain transformations in the nursing labor force affecting these people have bearing on the development of feminist theories of the sexual division of labor and on sociological theories of health care.

The four issues discussed are: 1) the expansion of the nursing assistant labor force and its implications for nursing as an occupation and profession, 2) the work of foreign-trained nurses in the United States and the significance of this for a world economy perspective for nursing, 3) the nursing shortage, and some feminist and sociological writings that contribute to an analysis of the issue, and 4) the relationship between nursing and medicine and two alternative approaches through which this division of labor can be explained sociologically.

\section{NURSING ASSISTANTS}

British sociologists Celia Davies (1979), Margaret Stacey (1982), and the contributors to Finch and Groves (1983) argue for a broad conception of health care work and workers, emphasizing that most health care work is done by women in both paid and unpaid capacities. They suggest that health care is a broader realm of work than can be encompassed even in definitions that include all paid health care workers, because this stops short of a recognition that mothers, wives, and daughters do most of a society's health care work. This is not to diminish the importance of nursing, but to reinforce its base in caring work. They accentuate the common bonds of all women health care workers as careers of the sick whose work is frequently unrecognized and unnamed.

Proceeding from this position, various categories of paid health care workers can also be conceptualized in terms of their common bonds, and the full range of nursing occupations can be explored holistically. If there are common features in the health care work of mothers and nurses, the relationship of registered nurses and nursing assistants is open to analysis from both a broad and a narrow conception of nursing. Are nursing assistants nurses? The answer can be approached in two ways.

One is to work within the formal definitions of occupational categories. In this case the two are distinct and registered nurses mark the proper occupational boundary of nursing. This is the position adopted explicitly by the American Nurses' Association, for example, and it is implicit in most medical sociology and health care literature, in which the nursing assistant is all but invisible. There are approximately 1.2 million registered nurses presently working; typically these are taken, as Fagin (1983:123) does, as the population of "employed nurses." Among new entrants to the field 20 percent study in diploma courses, 50 percent in associate degree schools and 30 percent in bachelor's degree programs (Hess, 1983:125).

This definition excludes the one-half million licensed practical nurses (Hess, 1983). It also does not count the 1,175,000 nursing assistants (Alexander, 1983:64) who constitute nearly as large a group as registered nurses. Nursing assistants are a decreasing portion of. hospital personnel (from 51 percent of nursing service in 1968 to 35 percent in 1979) (Aiken, et al., 1981:1616). Yet the job of nursing assistant, far from being phased out, is projected to become the second largest job category in the entire workforce by the end of the century, second only to secretaries, and larger in number and rate of growth than registered nurses. Alexander $(1983: 64)$ reports from Department of Labor projections that there will be 1,682,000 nursing assistant jobs compared to $1,542,000$ for registered nurses. This signifies a changing configuration of the overall nursing force, but also reflects changes in the location of health care work since almost all nursing assistants will be working in nursing homes and home health care. ${ }^{4}$ Nursing assistants are separated from registered nurses by education and 
state certification; one must have the diploma or associate's or bachelor's degree to take the state examination to become registered. So, in terms of formal criteria, registered nurses, licensed practical nurses, and nursing assistants comprise a 2.8 million person workforce that is divided in half, and only half are called nurses.

From another approach, that of working with nursing assistants, these formal criteria become quite blurred. There are, of course, bold reminders of the distinction, hierarchy and pay among them. Nursing assistants made from $\$ 3.50$ per hour (Frank, 1981:6), which is what I earned in all the places I worked, to $\$ 5.00$ in some places (Askin and Yuill, 1983). These near-poverty wages are a constant source of conversation and complaint, and create pauperization even within full-time wage work, a trend that Beechey (1978) notices regarding some emerging occupations for women. Still, while the pay distinction is very clear, others are obscure. Training is an example. Since state certification is becoming a requirement for nursing assistants as well as registered nurses (American Association of Nursing Assistants, 1983:9), nursing assistant students must attend a training program. Most of the assistants with whom I have worked, including myself, enrolled in one of the twelve approved programs in the region, attending at night for six months, paying $\$ 1000$ tuition, buying books and uniforms and, upon certification, became eligible to apply for work. It became apparent through many conversations with these women (and the very few men) that in the pursuit of their nursing careers they might otherwise have gone to college. But the ground shifted from under them in the historical shifts in nursing training.

During the last twenty years, nursing students have been able to rely on government support for loans through the Nurse Training Act, but funds for this have been all but eliminated (Green, 1983). Furthermore, recommendations by the Institute of Medicine's Commission on Nursing and Nursing Education (1983) are that funds be reduced for the basic training of registered nurses, and reserved for postgraduate training. In other words, nursing now means something different in terms of the career options that the government supports for these women. It means for many that nursing assistant school became the more viable option.

Also, in actual practice, most nursing assistants call the work that they do nursing. It is not mediated by much training in medical or management science, but it is continual tending to infirm people. The work involves ongoing relationships with patients, with intimate associations for years, even up to their deaths. As a human social relation what is this to be called if not nursing? Although it is the kind of work with which nursing began, it is now defined as an adjunct to it. At this point in the development of the nursing assistant position, a dilemma has evolved. There is a name for the new profession, but if they are not allowed to call what they do nursing, then their work activity is rendered nameless. The second largest workforce in the society is named as an adjunct or aide to something other than itself and defined by and in terms of the other. In the final section of the paper I will suggest two alternative sociological and political approaches to a resolution of this dilemma. First I wish to incorporate into the discussion some other subjects who have also experienced historical and conceptual shifts in the ground of their nursing work.

\section{NURSING IN THE WORLD ECONOMY}

A second group of caregivers whose everyday work life poses a challenge for a holistic frame of reference for nursing is that of foreigntrained nurses practicing in the United States. At a rate of 9,000 new foreign-trained nurses working in the U.S. each year (Clark, et al. $1980: 93)$, this is not a small portion of American nursing, nor is it a random phenomenon. Over half of all foreign nurses are from the Philippines (Sorrell, 1981:7). Those with whom I have worked received five years of training and the bachelor's degree in Manila. Most Filipina nursing students intend to emmigrate: in their country there are between forty and fifty nursing schools producing graduates (Sullivan, 1981:12). My co-workers signed with an agency in Manila expecting, even during their training, to work in nursing homes in the United States. Before they left they knew the exact nursing home and starting date for their work in the States, and, under the contract, they are not allowed to leave the place for one year. Although they were aware of this commitment, many were not aware of the six-month to one year wait before they could take the test to become registered and the four month wait after that to get the test results. Sorell (1981) reports tht 80 percent of Filipina applicants do not pass the test on their first attempt and must re-take it soon or face deportation. During this 1 to 2 year lag, these well-trained nurses are designated "graduate nurses." Paid less than registered nurses, they are not allowed to perform some of their tasks (e.g. pass medications) although when one observes them in emergency situations, it is clear that they are capable 
of doing so. Primarily, day to day, their work is identical with that of nursing assistants.

The experience of these people brings into focus at least two elements of contemporary nursing work. One is that the occupational boundaries which formally distinguish registered nurses from nursing assistants are easily permeated. To work with Filipina nurses is to hear continual jokes and complaints about their descent in status. "Five years of training so we could come here to pass trays," is one frequently heard refrain. The health care industry, especially the nursing home component, is provided with a steady supply of highly trained nurses who are not recognized or paid as legitimate nurses because they are not registered. As these industries become increasingly multinational, the importation of trained personnel for work in American facilities, the movement of labor from periphery to core nations, as Jonas and Dixon (1979) express it, is likely to increase. Meanwhile, these nurses, not registered and not nursing assistants, work in a vague, unnamed stratum somewhere between the two.

The more significant issue that these nurses serve to illustrate is that nursing is rapidly becoming part of the world economy. Just as nations are now sub-parts of a world system, and the import and export of labor power, including health care labor, is a constituent element of the growth of multinational capitalism (Elling, 1981), the sexual division of labor no longer stops at the boundaries of the nations (Kelly, 1981; Beneria and Sen, 1982). It may be important to see nursing in terms of the particular ways it is developing and being developed in the context of the emerging capitalist world system. At the least this can establish understandings among nurses from different countries of the relations which they have in common with one another vis-à-vis their corporate employers. In addition, from this perspective, it becomes clear that immigration and emigration of nurses, although nurses retain some decision-making power over where and when to move, is taking place within an increasingly intertwined multinational capitalist system of health care. From this different vantage point, the knowledge that foreign-trained nurses possess could become valuable; rather than second-class nurse, they become the ones with the wisdom, the experts in the game that nations and corporations play with their profession. They have already lived through commitments to contracts, drops in status, elaborate regulation procedures, and employment conditions set by some distant conglomerate to an extent that nurses from the First World can only imagine, but which may portend much of their own future. Thus to incorporate a world economy view into a sociological understanding of contemporary nursing may clarify the contours of the corporations for whom nurses will be working in the future. But to do this it is necessary that foreign-trained nurses be moved conceptually from the status of unnamed and invisible to that of expert subjects practicing a particular form of contemporary nursing. Many of these issues can be clarified further through a discussion of the nursing shortage debate.

\section{THE NURSING SHORTAGE}

There has been much discussion in the United States over the past decade about a nursing shortage. Recent summaries of the debatewhether there is or is not a shortage and what can be done about it-are available, from divergent points of view, in the work of Moccia (1982), Aiken (1983), Fagin (1983), Institute of Medicine (1983), O'Donovan and Bridenstine (1983), and several papers in Bullough, Bullough and Soukup (1983). Here I wish to pose a question about the question itself. To attempt an answer to the problem already accepts the logic of the question, but there is an element in it that deserves prior examination in terms of a sociology for nursing. With the primary purpose of this method being to "preserve the presence of the subject," the question is: are nurses the subjects in the nursing shortage debate? I wish to argue that they are not, and that the debate itself is an example of how nursing work is objectified when it is transformed into the frames of reference and language of capitalist hospital administration.

In the debate, nursing refers to a very small number of workers relative to the 1.2 million employed registered nurses, and to a select number of positions with particular training requirements. The figure most frequently cited as the indicator of the shortage, initially by the American Hospital Association (Aiken, 1983:1144), has been 100,000 unfilled positions. The shortage has been discussed as a crisis (Clark, 1980; Heilman, 1981; O'Donovan and Bridenstine, 1983), but the Institute of Medicine (1983; see also Aiken, 1983) concludes that the basic supply and demand for nurses is now in balance, in effect declaring that the crisis is over. However, The American Hospital Association, according to a recent survey of its hospitals (American Journal of Nursing, 1983:1610) finds that "one in three (hospitals) is still experiencing a shortage." Thus, the debate continues. But for whom? The parentheses around hospitals in this citation are in the 
quote, not added in this paper. Taking the subject and verb exactly as they are given here reveals something about the way the debate is constructed. Hospitals experience the shortage. Not only in this quote, but in the debate itself, hospitals are the subjects.

It is not difficult to create a scenario in which this recent crisis centers on hospitals, with nurses ending up as scapegoats in a situation over which they have little control. In the context of a multiplicity of hospitals and high technology units within them, often in the same geographical area, pressure has been intense to operate at a certain capacity to cover the cost of very expensive equipment and to show a profit. This model of separately owned and operated corporate enterprises has encouraged a duplication of services and fueled a drive toward competition through high technology (Waitzkin, 1983). There has been a lag between the proliferation of this technology and the trained nursepower to keep it running. A spokesperson for the National League of Nursing (Green, 1981:4) summarizes it, "hospitals need more nurses today to monitor technical equipment in critical care and other specialty units." This technology is labor-intensive (Aiken, 1983:1443) and it is precisely where hospitals as capitalist enterprises have concentrated their investment throughout the last decade. Solutions to the problem of staffing have varied for hospitals: some have met the staff requirements, others have closed down the units in the face of a patient-demand much lower than hoped because of the crisis in the larger political economy. As Aiken (1983:1440-41) explains it, "as general unemployment reached a post-depression high and millions of Americans lost their hospital coverage, occupancy rates in hospitals declined." Whatever the solutions, it is within this complex of activity that labor shortages or surpluses have been declared. The nursing shortage has been but one part of the crisis of capitalist production, which for many hospitals reached a genuine crisis of overproduction/underutilization. This is a mode of production problem, not a problem attributable to nursing.

Yet when the nursing shortage is taken out of this context and treated as an autonomous phenomenon it becomes reified, a things in itself rather than an intelligible part of a whole. The shortage, when seen as an isolated entity, assumes an ideological character that obscures the hospital as a protagonist in the crisis and implies that the shortage is one brought about by workers. With the logic of capitalist hospital structure taken as a given, the issue is reduced to what to do about the workers. Despite the data (Elder, 1983:14-15) showing that the supply of nurses has been increasing steadily, that the labor force participation is much higher for nurses than for women in general, and that more nurses are working in hospitals than ever before, still the freefloating ideology (that is, not grounded in the empirical organizational changes) that the crisis is a worker problem has generated an ethos in which nurses are posed as the active creators, even culprits, of the nursing shortage. Some accounts exemplify this perspective directly in their titles: "Nurse: Where Are You?" (NBC News, 1981), "The Handmaiden Revolt-The Nursing Staff Crisis." (O'Donovan and Bridenstine, 1983), "Florence Nightingale Wants You!" (Toufexis, 1981), "Nurse Scarcity Forces Cut in Care in New York Municipal Hospitals (Sullivan, 1981), and "Nurse Shortage Perils County Baby Care" (Van, 1980:2).

Within this climate many options opened for hospitals in dealing with their labor shortages. In addition to aggressive recruiting and some pay increases for the high technology positions (Green, 1981), the nursing shortage has also been associated with increased use of parttime and registry nurses (Moccia, (1982), faster pacing of nursing work (Campbell, $1983^{5}$ ), substituting nurses for jobs previously done by other personnel, as in the work of the nursing assistants whose ranks have diminished in hospitals (Aiken, et al., 1981), and, as suggested above, the recruitment of foreign-trained nurses (Sullivan, 1981). All of these actually reduce costs for hospitals. This would follow logically: when the shortage is framed from the outset as an issue of vacancies, with hospitals constructing the cost-benefit equation, the shortage begins in the vested interests of hospitals and ends with solutions that reinforce these interests.

The issue of the nursing shortage, then, can be seen as a particular discourse on nursing, with certain terms and social relationships already presupposed. It is a market discourse, with profit margins and labor costs, productivity, supply, demand, and vacancies. Nurses are entered into the debate as labor in the enterprise and subsumed within the goals and technological imperatives of medical corporations. The debate presumes, for example, that the proper place of nursing is hospitals. The Institute of Medicine (1983) recommends that funding for basic nurse training be phased out primarily on the evidence of the supply and demand projections of hospitals. Even as it recognizes a need for more nurses in inner-city impoverished regions, it does so in terms of hospital shortages (Aiken, 1983:1441). If recommendations from this federally funded report are followed, the government will cut support for basic nurse training since it has adopted corporate assumptions 
that nurses belong in hospitals, and hospitals project a balance, there is no further need for a government to support general nursing.

It could be argued, in contrast, that a shortage of nurses is a problem but that it is inappropriate to frame solutions in terms of hospitals in the first place. After all, nurses have resisted the identification of their work strictly within a hospital model throughout the century (Wagner, 1980; Melosh, 1982). From this perspective, one could argue that there is a severe shortage of nurses, but one that the hospital debate does not begin to address. Public health nursing, for example, could be increased geometrically if the health care priorities of the society were turned toward a preventive and away from a curative model. In nursing homes, nurses would be doubled and tripled in numbers if holistic care were the goal that determined staff ratios instead of the medical model that currently dominates (AnnandaleSteiner, 1979; Diamond, 1983). These scenarios seem outlandish only in the present context in which nursing is embedded in a corporate discourse which defines nursing and delimits the scope and conditions of its work based primarily on profitability. The sociology for nursing issue raised here is not whether there is or is not a nursing shortage, but who has the right to ask and answer the question. In this debate the question has been taken from nurses and given to those who determine thie size of hospital staffs. Optimistically, now that the crisis is declared over, perhaps nurses will generate a new discourse in which they are more actively involved in naming the scope and potential of their work. After the tumult over this hospital labor shortage has quieted, perhaps nurses will be able to identify the conditions of a nursing shortage based on the needs of a society, not just those of hospital corporations.

\section{NURSING AND. MEDICINE}

One overarching issue which contextualizes all of these controversies is the relationship of nursing and medicine. Like the nursing shortage, this is a socially constructed relationship, and the presuppositions made about it inform any vision of the organizational possibilities of health care work. Elling (1981) and Waitzkin (1983) write about medicine as a form of politics, invoking Rudolf Virchow's famous dictum that "medicine is a social science, and politics is nothing more than medicine in a larger scale." The same could be said about nursing, and the social science and politics may not be at all the same as medicine's. The question here is whether nursing is considered identical with medicine, different from but complementary to it, or opposed to it. There are social and political theories which could support any of these possibilities. Depending on which kind of theoretical underpinnings are attributed to the relationship of nursing and medicine, different explanations arise about why this division of labor exists. In turn, different resolutions arise for the controversies presented in the earlier parts of the paper.

One constituent element of this occupational separation is its division by gender. Fewer than $10 \%$ of the nursing labor force are men (U.S. DHEW, 1975). Moreover, gender dichotomies which permeate the society find their expression in this division: care and cure, humanist and scientist, service and diagnosis, continuous and episodic patient relations (Lynaugh and Bates (1973) elaborate over twenty pairs of dichotomous terms). Over time, gender has become institutionalized as an integral part of the organization of health services. Since the distinction is based so intricately in a gender dichotomy, some sociological theory of gender has to be either implicit or explicit in a rationale explaining why this division exists. This is the point at which the theoretical alternatives enter.

In sociology there are two theoretical traditions through which this division can be explained, a consensus and a conflict model. In feminist theory, a collary to these would be liberal and radical/socialist feminisms (Jaggar, 1983). ${ }^{6}$ These two traditions are rooted in the differences between liberal and socialist philosophy. The division between nursing and medicine can be explained within either tradition, but depending on which is chosen, the political implications of the relationship appear very different, as are the explanations of the work situations of nursing assistants, foreign-trained nurses, and hospital nurses. ${ }^{7}$ These two traditions provide a set of premises and presuppositions that allow us to see this division of labor as part of a larger sociocultural context; what is different is how the two identify that context.

Presently there are political strategies and a body of academic research and scholarship developing about nursing and medicine in both theoretical traditions. For example, two kinds of histories are written about the relation, one that emphasizes a progressive development toward mutually interdependent professions (Maclean, 1974; Bullough and Bullough, 1978), and one that underscores the continual conflict of worker and capitalist, unionism and professionalism, and women and men (Reverby, 1979; Davies 1980; Melosh, 1982). 
Regarding the relationship between registered nurses and nursing assistants, the liberal position would support the separation. This would be to enhance the professionalization of nursing, which necessarily involves differentiation among ranks and, over time, a smaller elite who are properly designated professional nurses. The rationale for the differentiation is knowledge and training, primarily in science, management, and human psychology, distinct from but not opposed to the knowledge base of medicine. In the other tradition, this very knowledge base is challenged, not so much that it should not exist, but that it should not dominate nursing. The Radical Nurses Group (Radical Nurses Group, n.d.) in England, for example, notes specifically in its organizational aims that the term "nurse" includes auxiliaries. They oppose a professionalism that subdivides "qualified nurse" and argue (24) that the "divisionism inherent in professionalism (is) bad for nurses and other workers and patients." Rather than align with science, this position moves "toward showing the value of the work which women traditionally do," primarily in trying to recoup and reconceptualize the value of caring work. They are supported in this by an emerging literature which puts caring work prior to science or management at the epistemological base of nursing (Leininger, 1981; Finch and Groves, 1983). In this conceptualization nursing assistants have a common base with registered nurses, and the work that they do is reconstituted as nursing. With nursing based in caring, nursing assistants' work becomes visible.

Foreign-trained nurses would be seen differently in the two positions as well. They can be seen as appropriately positioned in second-class nursing situations in a given country because of their relatively inferior grounding in science and fluidity with the new culture in which they are practicing. However, if the focus is shifted away from differences among nurses and toward their common purpose, and nursing is viewed through the prism of their experience, it becomes apparent that nurses share common bonds in having the conditions of their work defined by a capitalist medical system that now selects its workers from a world labor pool. Foreign nurses portend much about the future of multinational capitalist health services, and they understand particularly well that all nurses, to paraphrase Fuentes and Ehrenreich (1984) are women (and men) in the global factory of health care.

The shortage would also be approached differently in the two traditions. In one the capitalist structure of hospital care is taken as a given. In the other it is exactly that structure that needs to be transformed in order for nursing to develop. The one would assume health care to be appropriately conceived as a market phenomenon (e.g. Fagin, 1983; Aiken, 1983; Waitzkin, 1982). In the one, nursing is named as hospital work, while in the other, nurses struggle to remove nursing from the dominance of the curative, medical model of hospitals. As the Radical Nurses Group expresses it (17): "the definition of caring (within the present curative system) is very narrow . . . the 'caring' nurse can be seen as one who confronts the inequalities in housing, diet, health and safety at work, etc., and works politically to change them." In this conception there is a nursing shortage but not one that the hospital complex is able to define.

Each of these political postures is based on assumptions about the relation of nursing and medicine. In the liberal tradition they are considered separate but equal professions with different but complimentary tasks (Lynaugh and Bates, 1973; Geyman, 1977). The goal here is the coordination of the two domains into professional interdependence within the organizational structure of the market. The other would see the two in opposition, as a relation that institutionalizes the dominance of capitalists over workers and men over women (Gamarnikov, 1978; Jaggar, 1983), and, therefore, a division that ultimately must be dissolved. Simultaneously the positions imply different goals for health care. It is consistent with the liberal tradition that health care divisions of labor progress through history toward specialization and differentiation, and that their services be bought and sold in the context of the marketplace. The other tradition is opposed to this context, works toward breaking down divisions among profes- sionals, non-professionals, and lay people, and toward divorcing health care from a marketplace philosophy. In the radical position, nursing does not have a chance, nor do patients, when health care is made into a commodity, from which profits are made, appropriated from the sick, and produced through the labor of nurses. Thus, the Radical Nurses Group (13) makes it one of its fundamental aims "to defend the provision of free health care and oppose profit-making health care."

Such divergent philosophies and goals suggest that nursing is politically very alive at this moment in history. The struggles are by no means only internal to the organization of nursing. They are also symptomatic of the way gender and class relations are being confronted in the larger society as well, particularly in regard to transformations of 
women's wage labor and to the status of caring work. In this sense nursing, like medicine, is a form of politics.

\section{CONCLUSION}

This is not the place, nor is a sociologist the person, to choose which form of politics is appropriate for the people discussed in this paper. What I have suggested is that as these people and their work situations are discussed within these alternative philosophies, they emerge with different identities as contributors to society. As soon as their work is measured against criteria constructed from within the context of capitalist medicine, they become invisible and their work objectified. Nursing assistants, who deploy very little science or technology or skills of professional management in their work, have lost even the name of nursing in the medicalized context in which these criteria and nursing are equivocated. Foreign-trained nurses slip into the dark corners of the health care industry, literally and conceptually, unless that industry is itself seen as problematic for the practice of nursing; then they emerge as experts on current transformations of multinational capitalist health care and the place of nurses within it. Regarding the nurse shortage debate, nurses can be swept into a frame of reference in which their work is a part of the hospital, rather than hospitals a part of their work. In all of these cases, nurses and their work become defined in terms of something else. Their invisibility begins when they become defined by the institutions of capitalist medicine.

The purpose of the method of preserving the presence of the subject, as Smith $(1974 ; 1979 ; 1981)$ suggests, it is not abstract analysis, but the construction of a vision of the society that is useful to the subjects in question. It does not stop at the point where workers become named as something else, but makes that process part of the analysis. Thus a theory which bases its conceptions about nursing in a philosophy that presupposes the capitalist context has little to offer towards empowerment for nurses because it has made a decision about the way to view caring work and eliminates another perspective that might otherwise be theirs. The sociological task in this method is to display as vividly as possible that there is a choice. In producing their everyday work, nurses have a choice in naming it, because there are political and philosophical alternatives through which they can link their work to the larger society. A sociology that situates their lives within a framework that presupposes capitalist medicine has less to offer than one which holds that framework in question. In the former, nurses can become invisible; in the latter, to the extent that sociology enhances their range of choice, they remain active subjects. This is the difference between a sociology about nursing and a sociology for nursing

\section{FOOTNOTES}

1. An earlier version of this paper was presented at the British Sociological Association Annual Meetings, Manchester, April, 1982. My thanks to Mary Diamond Collins, Celia Davies, Judith Dilorio, Derek Gill, Alison Jaggar, Patricia O'Brien and T.R. Young for their comments on the earlier draft.

2. The citation is taken from Feuerbach: Opposition of the Materialist and Idealist Outlooks, by Karl Marx and Frederick Engels.

3. Formerly called nurses' aides, now officially called certified nursing assistants and nursing assistants in the United States and Canada, and auxiliary nurses in the United Kingdom.

4. See Occupational Outlook Handbook (U.S. Dept. of Labor, 1980-81).

5. Marie Campbell is following Smith and developing a sociology for nursing in a different but related way to that suggested here. See especially "The Political Economy of 'Productivity' in Hospital Nursing" (1983).

6. Jaggar's (1983) monumental work traces the philosophical roots of assump tions about gender relations. She distinguishes among liberal, Marxist, radical and socialist feminism. For simplicity I am combining the latter three to differentiate a liberal and a radical/socialist approach.

7. Perhaps it should be mentioned that there is also a "natural" explanation of the division of nursing and medicine, that the distinction is an extension of the natural differences between women and men. As Gamarnikov (1978) points out, the assumption that this division is natural is deeply woven into contem porary medical ideology and sociological theory. This position is not worth serious consideration; it reduces the relationship to biological or some other "natural" cause, and serves more as a rationale for domination than an expla nation of the division. See Gamarnikov (1978) for a critique of this position.

\section{REFERENCES}

Aiken, Linda $\mathrm{H}$.

1983 "Nursing's Future: Public Policies, Private Actions." American Journal of Nursing 83:1440-44

Aiken, Linda H., Robert J. Blendon and David E. Rogers

1981 "The Shortage of Hospital Nurses: A New Perspective." American Journal of Nursing $81: 1612-18$ 
Alexander, Charles P.

1983 "The New Economy." Time, May 30:62-70.

American Association of Nursing Assistants

1983 "Nursing Assistant Certification." Nursing Assistant 1, No. 2:9.

American Journal of Nursing

1983 "AHA Sees Shortage at 1 of 3 Hospitals." American Journal of Nursing $83: 1610$.

Annandale-Steiner, D.

1979 "Unhappiness is the Nurse Who Expected More." Nursing Mirror 29:11. Askin, Steve and Barbara Yuill

1983 "Cuts, Conditions Spur Union." In These Times, April 6-12:7-8. Beechey, Veronica

1978 "Women and Production: A Critical Analysis of Some Sociological Theories of Women's Work." Pp. 155-97 in Annette Kuhn and An Marie Wolpe (eds.), Feminism and Materialism: Women and Modes of Production. Boston: Routledge and Kegan Paul.

Beneria, Lourdes and Gita Sen

1982 "Class and Gender Inequalities and Women's Role in Economic Development-Theoretical and Practical Implications." Feminist Studies 8:157-76.

Bullough, Bonnie, Vern Bullough and Mary Claire Sokup (eds.)

1983 Nursing Issues and Nursing Strategies for the Eighties. New York: Singer.

Bullough, Vern and Bonnie Bullough

1978 The Care of the Sick: The Emergence of Modern Nursing. New York Prodist.

Campbell, Marie L.

1980 Book Review: People, Patients and Nurses (by Jennie Wilting), Resources for Feminist Research 9 (Nov): 42-3.

1983 "The Political Economy of 'Productivity' in Hospital Nursing." Paper presented at the Learned Societies Conference, University of British Columbia, June 1-4.

Clark, Matt

1980 "An Acute Shortage of Nurses." Newsweek, Sept. 22:93-95.

Davies, Celia

1979 "Comparative Occupational Roles in Health Care." Social Science and Medicine 13:515-21.

\section{Davies, Celia (ed.)}

1980 Rewriting Nursing History. London: Croom Helm.

Diamond, Timothy

1983 "Nursing Homes as Trouble." Urban Life 12:269-86.

Doyal, Lesley

1979 The Political Economy of Health, London: Pluto.

Elder, Ruth

1983 "What! Another Report on Nursing?" Pp. 12-21 in B. Bullough V. Bullough, and M.C. Sokup (eds.), Nursing Issues and Nursing Strategies for the Eighties. New York: Springer.
Elling, Ray

1981 "The Capitalist World System and International Health." International Journal of Health Services 11:21-52.

Fagin, Claire M.

1983 "The Nursing Shortage in Perspective." Health Affairs 2:121-3.

Finch, Janet and Dulcie Groves (eds.)

1983 A Labor of Love: Women, Work and Caring. Boston: Routledge and Kegan Paul.

Frank, Barbara

1981 "Fighting Nursing Homes for Women's Wages, Women's Lives." Off Our Backs, October:4-6.

Fuentes, Annette and Barbara Ehrenreich

1983 Women in the Global Factory. New York: Institute for New Communications.

Gamarnikov, Eva

1978 "Sexual Division of Labor: The Case of Nursing." Pp. 96-123 in Annette Kuhn and Ann Marie Wolpe (eds.) Feminism and Materialism: Women and Modes of Production. Boston: Routledge and Kegan Paul.

Geyman, John P.

1977 "Is There a Difference Between Nursing Practice and Medical Practice?" The Journal of Family Practice 5:935-6.

Gill, Derek G.

1982 "Human Sexuality, Ethical Issues and the Medical Profession." Mid-

Green, Lloyd American Review of Sociology 7:3-28.

1981 "How Hospitals are Taking a Turn for the Nurse." Chicago Sun-Times, April 19:4.

Heilman, Joan $\mathrm{R}$.

1981 "Nursing: Can we Solve the Crisis?" Parade, March 15:26-31. Hess, Arthur E.

1983 "Understanding Future Nurse Supply." Health Affairs 2:124-6.

Institute of Medicine

1983 Nursing and Nursing Education: Public Policies and Private Actions. Washington, D.C.: National Academy Press.

Jaggar, Alison $M$

1983 Feminist Politics and Human Nature. Totowa, New Jersey: Rowman and Allanheld.

Jonas, Susanne and Marlene Dixon

1979 "Proletarianization and Class Alliances in the Americas." Synthesis $3: 1-13$.

Kelly, Maria Patricia Fernandez

1981 "Development and the Sexual Division of Labor: An Introduction." Signs 7:268-78.

Leininger, Madeleine M. (ed.)

1981 Caring: An Essential Human Need. Thorofare, New Jersey: Charles B. Slack. 
Lynaugh, Joan E. and Barbara Bates

1973 "The Two Languages of Nursing and Medicine." American Journal of Nursing 73:66-9.

Maclean, Una

1974 Nursing in Contemporary Society. Boston: Routledge and Kegan Paul. Melosh, Barbara

1982 "The Physician's Hand" Work, Culture and Conflict in American Nursing. Philadelphia: Temple University.

Moccia, Patricia

1982 "The Case of the Missing Nurse." Health/PAC Bulletin 13, No. 5:15-23. NBC News

1981 "Nurse-Where Are You?" Broadcast on May 18

O'Donovan, Thomas R. and T. Patrick Bridenstine

1983 "The Handmaiden Revolt-The Nursing Staff Crisis." Health Care Management Review 8:75-79.

Radical Nurses Group

No "Feminism and Nursing." Medicine in Society 8:15-17 (This journal Date does not indicate year of publication).

Reverby, Susan

1979 "The Search for the Hospital Yardstick: Nursing and The Rationalization of Hospital Work." Pp. 206-25 in Susan Reverby and David Rosner (eds.), Health Care in America: Essays in Social History. Philadelphia: Temple University.

Smith, Dorothy E

1974 "The Ideological Practice of Sociology." Catalyst 8:39-61.

1979 "A Sociology for Women." Pp. 135-87 in Julia A. Sherman and Evelyn Torton Beck (eds.), The Prism of Sex. Madison, Wis.: University of Wisconsin Press.

1981 "The Experienced World as Problematic: A Feminist Method" The Twelfth Annual Sorokin Lecture, University of Saskatchewan, Saskatoon, January.

Sorrell, Lorraine

1981 "Nurses Face Deportation." Off Our Backs, February:7-9.

Stacey, Margaret

1982 "Who Are the Health Care Workers? Patients and Other Unpaid Workers in Health Care." Paper presented at the International Sociological Association Conference, Mexico City, August.

Sullivan, Ronald

1981 "Nurse Scarcity Forces Cut in Care in New York Municipal Hospitals." The New York Times, August 6:1, 12.

Toufexis, Anastasia

1981 "Florence Nightingale Wants You!" Time, August 24:37.

U.S. Department of Health, Education and Welfare

1975 Women in Health Careers. Washington, D.C.: Health Resources Admin. U.S. Department of Labor

1980-81 Occupational Outlook Handbook. Bulletin 2075. Washington, D.C.
Van, Jon

1980 "Nurse Shortage Perils County Baby Care." Chicago Tribune, August $3: 2$.

Wagner, David

1980 "The Proletarianization of Nursing in the United States, 1932-1946." International Journal of Health Services 10:271-90.

Waitzkin, Howard

1983 The Second Sickness: Contradictions of Capitalist Health Care. New York: The Free Press. 